\title{
Federalismo e educação no Brasil: subsídios para o debate
}

\author{
Antônio Cabral Neto \\ Alda Maria Duarte Araújo Castro \\ Maria Goretti Cabral Barbalho \\ Universidade Federal do Rio Grande do Norte
}

\section{Resumo}

Este artigo discute o federalismo, buscando compreender seus marcos conceituais, assim como a sua configuração no Brasil e as repercussões para a área de educação. Conclui-se que, nos últimos anos, particularmente, após a Constituição Federal de 1988, há uma reconfiguração do federalismo brasileiro com a inserção do município como ente federado e com autonomia para conceber os seus sistemas de ensino. Foram aprovadas normas e implementados programas que buscam consolidar 0 regime de colaboração entre os entes federados para o campo da educação. Todavia, o federalismo brasileiro, ao longo dos anos, não cumpriu, a contento, a sua função redis42 tributiva e supletiva, de modo que se observam condições de ofertas diferenciadas em todos os níveis educacionais.

Palavras-chave: Federalismo. Educação. Programas.

\section{Federalism and education in Brazil: grants for debate}

\section{Abstract}

This article discusses federalism, seeking to understand their conceptual frameworks as well as its setting in Brazil and the implications for the field of education. We conclude, in the last years, that, particularly after the 1988 Federal Constitution, there is a reconfiguration of Brazilian federalism with the insertion of the municipality as a federated entity and autonomy to think out their education systems. The standards and implemented programs approved seek to consolidate the regime of collaboration among federal agencies for the field of education. However, the Brazilian federalism, over the years, has not fulfilled, satisfactorily, its redistributive and supplementary function, so we observed conditions that differentiated offers at all educational levels.

Keywords: Federalism. Education. Programs. 


\section{Federalismo y educación en Brasil: subsidios para el debate}

\section{Resumen}

Este artículo aborda el federalismo, tratando de comprender sus marcos conceptuales, así como su ubicación en el Brasil y las implicaciones para el campo de la educación. Se concluye que en particular después de la Constitución Federal de 1988, hay, en los últimos años, una reconfiguración del federalismo brasileño con la inserción del municipio como entidad federada con autonomía para concebir sus sistemas de educación. Se aprobaron las normas y programas implementados que buscan consolidar el régimen de colaboración entre las agencias federales para el campo de la educación. Sin embargo, el federalismo brasileño, con los años, no ha cumplido a satisfacción su función redistributiva y complementaria, por lo que se observan condiciones diferenciadas de ofertas en todos los niveles educativos observados.

Palabras clave: Federalismo. Educación. Programas.

\section{Notas introdutórias}

modelo de federalismo adotado pelo Brasil vem, ao longo de sua constituição histórica, assumindo diferentes formas legais e institucionais, na perspectiva de construir mecanismos para a redução das desigualdades regionais, que se constitui em uma das funções dessa forma de organização do estado. Embora tenha havido, no país, algumas mudanças no quadro das disparidades regionais nas últimas décadas, elas estão presentes em todas as áreas, inclusive, na educação, comprovada nas estatísticas oficiais. Especificamente no campo da educação, a ausência de um Sistema Nacional de Educação cuja instituição vem sendo postergada, por décadas, pode ser considerada um fator que vem contribuindo para tal situação.

Desse modo, a discussão desenvolvida neste artigo parte da premissa de que o federalismo brasileiro, ao longo dos anos, não cumpriu a sua função redistributiva e supletiva. Isso possibilitou que os entes federados tivessem condições de ofertas diferenciadas em todos os níveis educacionais, aprofundando as desigualdades nessa área. Nos últimos anos, particularmente, após a Constituição Federal de 1988, foram adotadas medidas pelo governo brasileiro para formatar um regime de federalismo cooperativo. Com esse intuito, foram elaborados marcos normativos e programas para garantir o direito à 
educação e instituir um Sistema Nacional de Educação que funcione como mecanismo articulador do regime de colaboração.

Este artigo se propõe, portanto, a desenvolver uma reflexão circunstanciada sobre o federalismo, buscando compreender os seus marcos conceituais, assim como a sua configuração no Brasil e as repercussões para a área de educação. $\bigcirc$ artigo está organizado em três partes. A primeira desenvolve uma reflexão conceitual sobre federalismo com destaque para três de suas dimensões: relações intergovernamentais, regime de colaboração e coordenação federativa; a segunda discute aspectos do federalismo no Brasil, focando o debate, sobretudo, a partir da Constituição Federal de 1988; a terceira busca compreender como se configuram as estratégias do federalismo no campo da educação no Brasil, evidenciando as principais iniciativas governamentais cujo objetivo consiste em melhorar as condições efetivas do regime de colaboração.

\section{Notas sobre o federalismo e suas principais dimensões}

$44 \quad \bigcirc$ federalismo pode ser caracterizado como um sistema político e de organização territorial do Estado, que envolve um compartilhamento de poder entre a instância soberana e os demais entes federados, assumindo diferentes formas legais e institucionais, de acordo com o momento histórico e o espaço geográfico onde ele se desenvolve. No Estado Federativo, vigora, em princípio, a colaboração e o compartilhamento no processo de tomada de decisão entre a União e os demais entes federados, todavia, cada um dos níveis de governo mantém a sua autonomia. É válido ressaltar que os entes federados não são nações independentes, tampouco, somente instâncias administrativas. Trata-se, então, de um sistema político em que são distribuídos os poderes e as funções entre o governo central e os governos regionais, compartilhando tarefas articuladas entre si, com um objetivo comum (CURY, 2010).

sistema federativo, em princípio, não se baseia em relações hierárquicas entre esferas do poder políitico porque ele se organiza centrado na ideia de que se estabelecem relações entre iguais. Com fulcro nesse entendimento, supõe-se que não há relação de subordinação entre União, Estados e Municípios, considerando que esses entes devem se constituir como iguais; assim, espera-se que eles estabeleçam relações de colaboração. Nesse 
sentido, é oportuno assinalar que a soberania é um atributo imanente ao estado federal, portanto, exercida unicamente pela união. A autonomia, por sua vez, configura uma dimensão constitutiva dos estados federados que integram o sistema federativo.

Oliveira e Santana (2010), recorrendo às ideias de Anderson (1987), resume, nos seguintes termos, os princípios básicos do federalismo:

a) defende ou estabelece um governo central para todo o país e determinados governos regionais autônomos [...] para as demais unidades territoriais; b) distribui os poderes e as funções do governo entre os governos central e regionais. c) atribui às unidades regionais um conjunto de direitos e deveres; d) autoriza os governos de ambos os níveis a legislar, tributar e agir diretamente sobre o povo, e el fornece vários mecanismos e procedimentos para resolução dos conflitos e disputas entre os governos central e regionais bem como entre duas ou mais unidades regionais (OLIVEIRA; SANTANA, 2010, p. 91.

Segundo esses princípios, o estado federativo "[...] supõe uma estrutura [... ] sustentada por uma soberania compartilhada" (ABRÚCIO, 2005, p. 43). É fato, porém, que há certo desequilíbrio no que se refere ao poder e à autonomia dos governos estaduais e municipais frente à União, considerando que ela assiste, financeiramente, essas instâncias. Contudo, o pacto federativo deve propiciar maior igualdade entre os entes no que diz respeito à formulação e à implementação de ações, programas ou políticas públicas.

Como preleciona Abrúcio (2010), três elementos são essenciais para a efetivação do sistema federativo: a) a compatibilização entre autonomia e interdependência dos entes federados, o que supõe, necessariamente, a existência de, no mínimo, dois níveis de governos autônomos e a necessidade de cooperação intergovernamental e de ações voltadas à integração nacional; b) a garantia da diversidade sociocultural e ou da redução das assimetrias socioeconômicas entre as esferas governamentais; c) a exigência de que as políticas públicas devam ser organizadas com vistas a garantir a coordenação entre todos os atores territoriais. Essa exigência decorre do fato de que existem vários problemas de ação coletiva que não podem ser resolvidos por, apenas, um nível de governo.

Nesses termos, a organização dessa forma de Estado pressupõe a existência de autonomia entre os entes federados e uma relação de cooperação 
intergovernamental, articuladas entre si, para garantir a proposição de ações e a criação de estratégias que favoreçam a consecução dos objetivos comuns. Para isso, torna-se necessário garantir os direitos dos estados e dos municípios, mediante uma Constituição que celebre o pacto entre os entes federados. Ademais, deve-se criar arenas institucionais que permitam aos governos federal, estaduais e municipais deliberar, negociar e decidir sobre assuntos com impacto nacional, regional e local. Por fim, a execução das políticas públicas deve ser realizada em regime de colaboração entre as unidades governamentais, assumindo a participação nas ações de forma coletiva (ABRÚCIO, 2010).

A institucionalização de um regime federativo requer, necessariamente, a constituição de pactos entre as diferentes instâncias de governo, pautados no regime de colaboração e coordenação entre essas instâncias. Como prelecionam Abrúcio e Franzese (2007), o arranjo territorial de poder envolve um

[...] acordo capaz de estabelecer um compartilhamento da soberania territorial, fazendo com que coexistam, dentro de uma mesma nação, diferentes entes autônomos e cujas relações são mais contratuais do que hierárquicas. O objetivo é compartilhar o princípio de autonomia com o de interdependência entre as partes, resultando numa divisão de funções e de poderes entre os níveis de governo (ABRÚCIO; FRANZESE, 2007, p. 41).

Uma das principais dificuldades registradas na literatura sobre esse tema diz respeito às relações estabelecidas entre o governo nacional e os governos subnacionais, porque eles não são entes plenamente autônomos. Desse modo, a constituição de um sistema federativo requer o necessário estabelecimento de uma relação de interdependência entre os entes federados que permita, ao mesmo tempo, a efetivação da repartição de responsabilidades e a garantia da integralidade do Estado nacional exigindo, portanto, a construção de pactos. Esse também é o entendimento de Elazar para quem,

[...] em essência, um arranjo federal é uma parceria, estabelecida e regulada por um pacto, cujas conexões internas refletem um tipo especial de divisão de poder entre os parceiros, baseada no reconhecimento mútuo da integridade de cada um e no esforço de favorecer uma unidade especial entre eles (ELAZAR, 1987, p. 5).

Reforça-se, assim, o argumento de que o princípio da soberania compartilhada deve assegurar, necessariamente, a autonomia dos governos e a 
interdependência entre eles. Como diz Abrúcio (2005, p. 14), a peculiaridade da federação reside exatamente na "[... ] existência de direitos originários pertencentes aos pactuantes subnacionais - sejam estados, províncias, cantões ou até municípios, como no Brasil." Por isso, como reafirma o mencionado autor, "[...] esses direitos não podem ser arbitrariamente retirados pela União e são, além do mais, garantidos por uma Constituição escrita, o principal contrato fiador do pacto político-territorial" (ABRÚCIO, 2005, p. 15). Para efetivação do federalismo, conforme Cunha (2004, p. 6), torna-se imperativo o reconhecimento da autonomia de cada uma das esferas territoriais de poder, mas, sobretudo, a "[...] construção de instituições, regras, culturas e relações entre governos, de maneira a permitir formas de cooperação e coordenação federativa."

Nessa perspectiva, três requisitos articulados sobressaem e são fundamentais para que se instaure um regime com características federalistas: as relações intergovernamentais, o regime de colaboração e a coordenação federativa.

Quanto às relações intergovernamentais, elas podem ser entendidas como o conjunto de ações de interpenetração e compartilhamento na formulação e execução de políticas públicas entre diferentes unidades governamentais em sistemas federativos específicos.

Em todas as federações, como preleciona Anderson,

[...] a interdependência é inevitável e significativa. É marcante, particularmente, nas federações cujos governos subnacionais implementam muitos programas ou leis federais, onde a competência comum ou conjunta é exercida em diversas áreas, e onde as unidades constitutivas são consideravelmente dependentes de transferência condicionais do governo central (ANDERSON, 2009, p. 89).

No sistema federativo, como diz (PIERSON, 1995), cada um dos entes representa locais autônomos de autoridade com capacidade para formular políticas próprias e, também, para influenciar as políticas que emergem do poder central. Nessa dinâmica, em que coexistem diferentes âmbitos de poder, instauram-se, como assinala Almeida (2001), formas peculiares de relações intergovernamentais, constitutivamente competitivas e cooperativas, marcadas tanto pelo conflito de poder quanto pela negociação entre as esferas de 
governo. Portanto, cooperação e competição são marcas imanentes às relações intergovernamentais.

A cooperação, como adverte Abrúcio (200 1), não significa a imposição unilateral de ações conjuntas. Para o autor, a cooperação é um mecanismo necessário dada a sua possibilidade de fortalecer os laços constitutivos da federação e pela natureza compartilhada das políticas públicas em Estados sob esse regime. Com essas características, as práticas de cooperação permitem otimizar a utilização dos recursos comuns, auxiliar os governos menos capacitados ou mais pobres na realização de algumas tarefas, além de permitir $\mathrm{o}$ ataque a comportamentos financeiros predatórios e possibilitar o acesso a informações sobre experiências exitosas no âmbito da administração. $\bigcirc$ modelo cooperativo contribui, sobremaneira, para aumentar a possibilidade no que se refere à efetivação de maior simetria entre os entes territoriais (ABRÚCIO, 2005).

A competição, por sua vez, não se apresenta como uma luta sem limites entre as unidades nacionais e subnacionais. Por vezes, a competição permite a criação de mecanismos de controle mútuo entre os entes federados, especialmente quando há riscos de perdas unilaterais de alguns dos atores 48 governamentais nos processos de negociação e decisões compartilhadas, de enrijecimento das relações intergovernamentais, de redução das possibilidades de inovação por parte dos governos locais e de enfraquecimento do controle entre os governos.

Desse modo, "[...] as federações requerem determinadas formas de competição entre os níveis de governo [...]" (ABRÚClO, 2005, p. 45), no sentido de evitar excessos nos movimentos corporativos, bem como práticas de paternalismos ou parasitismos de uns entes com outros. No entanto, é preciso ficar atento aos problemas das competições sem medidas, que podem afetar a solidariedade entre os entes, e, sobretudo, agravar a ação redistributiva e a guerra fiscal entre o plano nacional e subnacional. De modo geral, a adequação entre essas tendências, competitivas e cooperativas, como assinala Abrúcio (2005), parece ser o melhor caminho a ser trilhado na efetivação das relações intergovernamentais.

No que concerne ao regime de colaboração, pode-se afirmar que ele é imanente ao federalismo como cooperação. Ele se constitui na estratégia edificada para propiciar o estabelecimento de relações democráticas 
entre os entes, teoricamente, iguais e autônomos, com base em uma estrutura horizontal e de cooperação. $\bigcirc$ federalismo cooperativo se caracteriza pela coexistência de arenas com abrangências diferenciadas e se impõe a necessária relação entre elas. A cooperação, conforme Franzese (2010), relaciona-se, em princípio, a uma obrigatoriedade de que os governos trabalhem juntos, não por opção, mas por força dos dispositivos constitucionais e pela dinâmica do desenho federativo em que se incluem. É nesse sentido que a autora atesta a possibilidade de se evidenciar uma cooperação coercitiva, ou seja, uma cooperação forçada, não baseada em relações pactuantes, ou uma cooperação antagônica, nas quais os governos trabalham juntos, mas não mediante relações amigáveis, muitas vezes perseguindo diferentes objetivos.

Com essa feição, o perfil de cooperação apontado, nesse modelo, acaba se distanciando sempre da ideia de harmonia permanente entre os entes, deixando transparecer que tais relações assentam-se em constantes exercícios de negociação entre as esferas, além de reconhecer, nessa prática, a existência de momentos de antagonismo e competição. A colaboração federativa "[...] se traduz no modelo de distribuições e exercício das competências concorrentes e comuns, devendo a tomada de decisões e o exercício das competências ser conjuntas e não isoladas" (ARAÚjO, 2010).

Referente à coordenação federativa, observa-se que o seu exercício enfrenta conflitos e dilemas expressos em aspectos, tais como: as exigências por melhor desempenho governamental sob a pressão simultânea por economia, eficiência e efetividade na gestão das políticas públicas; o aumento das demandas por maior autonomia dos governos locais marcadas por constantes lutas contra a excessiva centralização e uniformização, ao mesmo tempo que se tenta evitar problemas com a fragmentação e o descontrole nos entes subnacionais; e, por fim, a necessidade de aliar o acompanhamento dos processos de interconexão dos governos locais com outras estruturas de poder que não o governo central como as forças transnacionais, com o necessário reforço das instâncias nacionais para uma melhor inserção internacional do país mediante os impactos da globalização (ABRÚCIO, 2005; FRANZESE, 2010$).$

As federações, segundo Abrúcio (2005), devem lançar mão de algumas estratégias fundamentais para assegurar a coordenação federativa e o funcionamento das relações intergovernamentais. $\bigcirc$ autor refere-se à necessidade de equilibrar as formas de cooperação e competição, instaurando em relação à cooperação alguns mecanismos de parceria que, em primeiro 
plano, sejam aprovados pelos vários níveis de governo. Para esse autor, essa coordenação pode ocorrer, por meio de regras legais, que obriguem os atores a compartilhar decisões e tarefas, pela existência de fóruns onde se façam representados os próprios entes, pela criação de uma cultura que figure o respeito mútuo entre as unidades e pela negociação compartilhada de um plano intergovernamental. Nesse processo, o governo federal pode exercer seu papel de coordenador.

Desse modo, a intervenção, a negociação e o compartilhamento podem ser encarados como peças do regime de colaboração. Nesse formato, a colaboração passa a incorporar os sentidos para além da execução; assume, às vezes, práticas de participação decisórias nos destinos das políticas e nas suas formas de materialização e de tomada de posição.

As relações intergovernamentais ou cooperação intergovernamental no sentido da criação de mecanismos cooperativos para a formulação e execução de políticas não podem prescindir dos seguintes elementos: distribuição de poder, distribuição de autoridade, e distribuição de recursos. É, nesse sentido, que as práticas de interdependência (autonomia) e interpenetração (relações cooperativas) podem tomar curso na construção de um federalismo

50 assentado em relações colaborativas entre os âmbitos nacional e subnacional, em especial, com os municípios.

governo federal tem prerrogativas específicas para manter 0 equilibrio federativo e os governos intermediários igualmente detêm forte grau de autoridade sobre as instâncias locais ou comunais. Mas a singularidade do modelo federal está na maior horizontalidade entre os entes, devido aos direitos originários dos pactuantes subnacionais e à sua capacidade política de proteger-se. Em poucas palavras, processos de barganha afetam decisivamente as relações verticais em um sistema federal (ABRÚCIO, 2005, p. 15-16).

Por fim, é possível asseverar que a coordenação federativa, como bem assinala Arretche (2004), pode concretizar-se mediante regras legais que obriguem os entes federados a compartilhar decisões e tarefas (definição de competências no terreno das políticas públicas, por exemplo), pela existência de fóruns federativos, com a participação dos próprios entes, como os senados em geral, ou que eles possam acionar na defesa de seus direitos, como as cortes constitucionais. Realça, ainda, a referida autora que a construção de 
uma cultura política, baseada no respeito mútuo e na negociação no plano intergovernamental, é outro elemento importante para o sucesso da coordenação federativa.

Em resumo, pode-se assinalar que relações intergovernamentais, regime de colaboração e coordenação federativa são dinâmicas que se articulam, intrinsecamente, na organização e no funcionamento do estado federativo. A forma como essas três dimensões se manifestam variam, de país para país, e, no seu interior, de acordo com cada conjuntura econômica e política. Tais particularidades estão exaradas em uma constituição que determina legalmente competências aos vários níveis de governo, assegurando, portanto, a autonomia de cada um deles.

\section{O federalismo brasileiro: aspectos de suas particularidades}

As Constituições brasileiras de 1891, 1937, 1946, 1967 e 1988 asseguraram a configuração republicana do Estado. Não obstante, o desenrolar do processo histórico da estrutura políitica do Estado brasileiro deixa perceber um movimento cíclico de centralização/descentralização do poder. Nessa perspectiva, o Estado federativo, no Brasil, tem adotado diversos contornos e arranjos políiticos e territoriais que foram sendo construídos ao longo da história. Desse modo, uma das principais características do sistema federalista é a flexibilidade, o que pode ser exemplificado pela sucessão entre centralização e descentralização políitica e econômica, constatada nos períodos de intervenção militar e, depois, na redemocratização do país. Observa-se, pois, que o federalismo brasileiro segue as transformações, pelas quais passa o sistema político, estando estritamente vinculado a este.

De acordo com Souza (2010),

No Brasil, ao contrário dos EUA, partiu-se de uma ordem centralizada, que era o Estado unitário do período imperial, para uma ordem federativa de divisão de poderes e competências em 1889, num processo centrípeto. A conversão do Estado unitário em Estado federado foi um processo lento e gradual. Houve uma adaptação dos princípios e instituições federalistas, de modo a manter os interesses e privilégios das elites agrárias, industriais e burocráticas, que organizaram a independência e controlavam o Império (SOUZA, 2010, p. 6). 
Os fundamentos atuais do Estado Federativo brasileiro estão determinados no art. $3^{\circ}$ da Constituição Federal de 1988, obedecendo a uma matriz cooperativa de repartição de competências, em que coexistem competências concorrentes e comuns entre as unidades federativas, tanto nos aspectos legislativos, quanto nos aspectos administrativos e tributários. No que se refere às competências comuns, União, Estados e municípios partilham funções e prestação de serviços nos setores da saúde, saneamento, educação, cultura e meio-ambiente. Quanto às competências concorrentes, essas se constituem em compartilhamento de capacidades políticas legislativas entre os entes federados, permitindo que todos possam exercer a possibilidade de legislar sobre os mesmos temas nos âmbitos dos seus interesses prevalentes (DRIGO, 2013).

Verifica-se, por outro lado, que há algumas prerrogativas específicas da União, a exemplo da legislação sobre meio ambiente, e outras em que podem legislar de forma concomitante, a exemplo da educação, configurando o designado federalismo cooperativo, ou integrado, de cunho tridimensional. Isso evidencia um Estado peculiar que tem como uma das principais particularidades o fato de ser uma federação com três esferas constitucionais de poder: a federal, a estadual e a municipal.

52 Como assinala Araújo (2010, p. 234), essa estrutura de repartição de competência é complexa na medida em que o pacto federativo brasileiro se aproxima "[...] do modelo alemão [...]", em que, na divisão de responsabilidades entre os níveis da federação, os estados são responsáveis pela execução dos principais serviços públicos, como educação, saúde e segurança social, mas preserva as técnicas de repartição de competências típicas do federalismo norte-americano, em que se estabelecem competências fixas e reduzidas à União, sendo as demais competências distribuídas às unidades subnacionais.

Tal padrão coloca no centro da agenda a construção de mecanismos de coordenação/cooperação que incluam os estados e os municípios bastante heterogêneos, tanto do ponto de vista econômico-tributário quanto do político e social. $\bigcirc$ modelo assumido, no país, justifica-se na perspectiva de equilibrar os conflitos existentes na federação, de buscar o comedimento de poderes entre a União e os Estados membros por meio de práticas de colaboração e distribuição de competências, de forma planejada e com objetivos comuns. Como defende Saviani (201 1, p. 76), "[...] aquilo que caracteriza a federação é a unidade de vários estados que, preservando suas respectivas 
identidades, intencionalmente são articulados tendo em vista assegurar os interesses e necessidades comuns."

Embora a Constituição da República Federativa do Brasil de 1988 - CF/1988 tenha, como princípio, a organização horizontal dos entes federados, o seu funcionamento é muito complexo, tendo em vista a conformação federativa que caracterizou a construção do estado brasileiro. A CF/1988 ampliou o conceito de federação, atribuindo, também, aos municípios a condição de entes federativos.

Para Araújo (2010), essa nova configuração do federalismo brasileiro trouxe duas complicações para o País: a primeira diz respeito ao tamanho e a heterogeneidade da federação brasileira, constituída por estados e municípios de diferentes portes e que, na sua maioria, sobrevivem com repasses de fundos de participação; e a segunda refere-se à falta de clareza e de regulamentação do que seria, realmente, um regime de colaboração. Ainda, para autora, no Brasil, é possível associar as várias formas de complexidades às matrizes que assume o federalismo a partir das relações intergovernamentais entre os entes federados.

Assim, pode-se evidenciar, nesse cenário, no que se refere à repartição de competências, os diferentes tipos de federalismo: o dual, caracterizado pela repartição de competências entre os entes federados em que se estabelece uma relação de coordenação; o centralizado, em que as unidades subnacionais são agentes administrativos do governo central; e o cooperativo, no qual os entes federados e o governo nacional têm ação conjunta e capacidade de autogoverno.

De acordo com Novelino (2013, p. 71 1), a CF/ 1988 apresentou certa inovação, entretanto conservou os fundamentos tradicionais das Constituições passadas, assumindo como diretriz para a repartição de competências na federação brasileira o princípio da predominância do interesse. Assim,

a competência para tratar de assuntos de interesse nacional ou predominantemente geral foi atribuída à União. [...] A competência para tratar de assuntos de interesse predominantemente local foi atribuída aos Municípios (CF, art. 30, I). A competência residual para tratar de assuntos de interesse regional ficou a cargo dos Estados (CF, art. 25, $\S 1 \%$. Ao Distrito Federal, em razão de sua natureza híbrida, foi atribuída competência para tratar de assuntos de interesse regional e local (CF, art. 32, $\S 1^{\circ}$ ) (NOVELINO, 2013, p. 7111 . 
Por apresentar grande complexidade, a repartição de competência torna-se incapaz de resolver todas as dificuldades dela advindas. Entre as inúmeras razões que concorrem para tal situação, ressalta-se que, em determinados momentos, há um interesse cuja predominância é equivalente para mais de uma unidade federativa (NOVELINO, 2013).

Segundo Abrúcio (2010, p. 46), após a Constituição Federal de 1988, o federalismo brasileiro assumiu características de uma descentralização bastante pulverizada e com frágil coordenação entre os entes federativos. Em decorrência desse formato, distinguem-se duas situações,

[...] de um lado, um jogo defensivo e não cooperativo, e, de outro, a tentativa de criar forma de coordenação entre os níveis de governos. De todo modo, o resultado desse processo foi a instauração de um federalismo compartimentalizado, no qual vigora uma ação estanque de cada esfera governamental, com poucos incentivos para parceria e entrelaçamento entre as unidades federadas. Entretanto, outra tendência intergovernamental pode ser observada nos últimos vinte anos. Trata-se da tentativa de aumentar os mecanismos de cooperação e coordenação entre os níveis de governo (ABRÚCIO, 2010, p. 48-49).

Numa visão mais abrangente, Costa (2010, p. 78) sustenta que "[...] ao longo do século XX, o federalismo brasileiro e suas relações intergovernamentais foram marcados pela oscilação entre regimes autoritários centralizadores, e regimes liberais descentralizados" [...], o que, segundo o autor, acabou produzindo clara instabilidade na dinâmica institucional no Brasil.

Como assinala Caffarate (2002), as formas de colaboração exercidas pela coordenação federativa, no país, trazem as marcas da centralização, uma das características do federalismo brasileiro (federalismo centrípeto). Ou seja, um federalismo direcionado para o centro, caracterizando uma centralização consubstanciada na predominância de atribuições para a união (CAFFARATE, 2002). Essa mesma tendência é observada por Dallari (1995), ao afirmar que a supremacia do poder federal, no país, é estabelecida de modo indireto, porque a Constituição brasileira, embora mantenha a equivalência formal entre união, estados e municípios, a distribuição de competências demonstra, de forma incontestável, a supremacia do poder federal. Segundo ele, essa supremacia é decorrente de duas causas: a enumeração de competências federais que é muito ampla e abrange quase tudo o que é essencial em termos de direitos e 
deveres fundamentais, economia e finanças, bem como sobre a organização e ação política; e o fato de a União ter competência para fixar regras gerais de competências estatais.

Na forma de organização federada, deve-se pôr em evidência a necessidade de se especificar, claramente, as competências concorrentes e comuns. Atinente às primeiras, como indica Bercovici (2003), o princípio da descentralização, consubstanciado na Constituição Federal de 1988, desenha uma federação de estados e municípios coordenados pela união, mas não a ela subordinados. Aí, reside o fulcro das competências concorrentes que imprime concretude ao princípio da coordenação federativa visando à edificação da unidade nacional.

A definição de normas de cooperação recíproca entre os entes federados pode contribuir, substancialmente, para o fortalecimento do regime federativo. Nesse aspecto, constata-se que, na situação brasileira, como lembra Marques (2012, p. 13), não há, no Brasil, "[...] acordo federativo claro sobre a repartição e o compartilhamento das responsabilidades para o exercício da competência que é comum." E isso se constitui em um obstáculo para "[...] promover a qualidade e a quantidade da oferta de um serviço público estratégico para o projeto republicano da nação brasileira" (MARQUES, 2012, p. 11 ).

O artigo 23 da Constituição Federal de 1988 (com as modificações introduzidas pela Emenda Constitucional n 53/2006) já determina que União, Estados, Distrito Federal e Municípios possuem competências comuns. No parágrafo único desse mesmo artigo, foi especificado que serão fixadas normas, por meio de leis complementares, para disciplinar o processo de cooperação entre os entes federados, com o objetivo de promover o equilíbrio do desenvolvimento e do bem-estar em âmbito nacional. O que foi exarado no ordenamento jurídico contempla o princípio de colaboração entre os entes federados, mas, como asseveram Oliveira e Souza, (2010, p. 21-22) "[... não encontra, na prática, mecanismos de indução ou de obrigatoriedade, posto que, em princípio, estes são autônomos. Assim, se os dirigentes dos diferentes sistemas não estiverem predispostos a colaborar entre si, isso não ocorre."

As formas de colaboração concretizadas no país trazem as marcas de uma coordenação federativa que Oliveira e Souza (2010) nominaram de a colaboração que vem do centro, portanto, com características diferentes da cooperação federativa. Isso porque, como lembra Araújo (2010), a colaboração 
federativa deve ocorrer por meio da distribuição e do exercício das competências concorrentes e comuns. Desse modo, a tomada de decisão e o exercício das competências devem ser conjuntas e não isoladas.

Na configuração institucional, decorrente da matriz expressa pela Constituição Federal de 1988), o modo de interação entre as unidades federadas mostra-se numa conformação caracterizada como um conjunto de espaços de negociação, coordenação e produção de políticas e serviços públicos, funcionando horizontal, vertical e setorialmente nas diferentes esferas de governo. Decorre daí as relevantes transformações no modo de atuação dos entes federados, induzidas pelos diversos interesses, de cooperação ou de competição.

Considera-se, portanto, que o país adotou um modelo de federalismo com tendência ao centralismo; visto que ainda não há precisão quanto à clareza na definição das competências, dado que estas ora se entrelaçam, ora se superpõem, fato que possibilita à União responder ou dispor de mais competências e, desse modo, determinar e exigir, dos entes federados, o cumprimento das competências (SOUZA, 2010). Nessa perspectiva, torna-se premente demandar aos Estados e Municípios condições para elaboração e implementação de políticas públicas. Sem a manutenção de um equilíbrio entre autonomia política/

56 administrativa e autonomia financeira, a concepção de pacto federativo perde sentido.

\section{Implicações do federalismo no campo educacional: marcos legais e programas}

A Constituição brasileira de 1988 pode ser considerada um marco significativo na reorganização do estado brasileiro. A sua aprovação resultou na descentralização de poderes e encargos bem como firmou a necessidade de colaboração entre os entes federados para que, entre outros fatores, fossem estendidas à população, de forma mais equilibrada, conquistas, tais como: acesso ao ensino obrigatório e gratuito como direito público subjetivo, gratuidade do ensino público em todos os níveis, valorização do magistério e gestão democrática da educação pública.

No que se refere à competência dos entes federados para com os sistemas educacionais, a Constituição Federal de 1988 instituiu no seu art. 211 , que, a União, os Estados, o Distrito Federal e os Municípios deverão organizar, 


\section{Antônio Cabral Neto | Alda Maria Duarte Araújo Castro | Maria Goretti Cabral Barbalho

em regime de colaboração, seus sistemas de ensino. Especificamente, os parágrafos $1^{\circ}$ e $4^{\circ}$ estabelecem:

$\S 1^{\circ}$ A União organizará o sistema federal de ensino e o dos Territórios, financiará as instituições de ensino públicas federais e exercerá, em matéria educacional, função redistributiva e supletiva, de forma a garantir equalização de oportunidades educacionais e padrão mínimo de qualidade do ensino mediante assistência técnica e financeira aos Estados, ao Distrito Federal e aos Municípios; $\S 4^{\circ} \mathrm{Na}$ organização de seus sistemas de ensino, a União, os Estados, o Distrito Federal e os Municípios definirão formas de colaboração, de modo a assegurar a universalização do ensino obrigatório' (BRASIL, 1988, p. 37).

conteúdo desses parágrafos evidencia uma preocupação do legislador em estabelecer as competências que deverão ser assumidas pelos entes federados na constituição dos seus sistemas de ensino. No entanto, a definição de competências gerais, sem estabelecimento de atuação de cada instância federada, permitiu a realização de ações sobrepostas. Posteriormente, as modificações advindas das Emendas Constitucionais n. 14, de 12 de dezembro de $1996^{\prime}$ e n. 59, de 11 de novembro de 2009², definiram, com mais clareza, o regime de colaboração, estabelecendo competências para os entes federados por nível de ensino.

Outro marco importante no campo da educação foi a aprovação da Lei de Diretrizes e Bases da Educação Nacional (LDB) n. 9.394, de 20 de dezembro de 1996, promulgada em um contexto histórico de mudanças no papel do Estado sob a influência do ideário neoliberal, momento em que foi simplificado o arcabouço legal vigente e estimulada a ação de agentes públicos e privados na promoção da qualidade do ensino.

Quando trata da Organização da Educação Nacional no Título IV, a Lei de Diretrizes e Bases, n. 9.394, de 20 de dezembro de 1996, favorece a implantação do regime de colaboração ao prever no art. $8^{\circ}$ que a União, os Estados, o Distrito Federal e os Municípios organizarão, em regime de colaboração, os respectivos sistemas de ensino, e ainda no $\S 1^{\circ}$ do mesmo artigo, determina, que caberá à União a coordenação da política nacional de educação, articulando os diferentes níveis e sistemas e exercendo função normativa, redistributiva e supletiva em relação às demais instâncias educacionais. Estabelece ainda, no art. $9^{\circ}$ que a União incumbir-se-á de elaborar o Plano 
Nacional de Educação, em colaboração com os Estados, o Distrito Federal e os Municípios.

$\bigcirc$ primeiro Plano Nacional de Educação (Lei n 10.172, de 9 de janeiro de 20011, oriundo das determinações da Lei de Diretrizes e Bases n 9.394, de 20 de dezembro de 1996, elaborado para o período de $2001 / 2010$, estabelece uma integração de esforços englobando três dimensões para a consecução dos seus objetivos: a) a articulação entre a União, os Estados e os municípios, o que seria feito através do regime de colaboração; b) a articulação entre os governos e as organizações não governamentais, incluindo a iniciativa particular, que faz parte do sistema e c) entre setores responsáveis pelas políticas sociais. Ainda no seu art. 20, a Lei (BRASIL, 2001, p. 01 l prevê que os "Estados, o Distrito Federal e os Municípios deverão, com base no Plano Nacional de Educação, elaborar planos decenais correspondentes [...]" e que a União, em articulação com os Estados, o Distrito Federal, os municípios e a sociedade civil, procederá a avaliações periódicas da implementação do Plano Nacional de Educação (art. 3\%.

As avaliações feitas do PNE/2001 mostram que não foi viabilizada a maioria das propostas previstas no Plano. A última avaliação do Plano 58 Nacional de Educação (200 1-2010), realizada pelo MEC (2008), assim como estudos efetivados por pesquisadores como Dourado (2011), apontam como principais problemas para a não consecução, ou a consecução parcial, dos objetivos e metas previstos no Plano Nacional de Educação (2001-2010), a gestão, o financiamento da educação e o regime de colaboração.

Nesse sentido, Dourado (2011) sinaliza que, ao definir grandes metas, indicando intensos desafios para a melhoria da educação nacional, o PNE (2001) configurou um plano formal, marcado pela ausência de mecanismos efetivos de financiamento. Os Planos estaduais e municipais de educação não se realizaram como política concreta $e$, consequentemente, não contribuíram para a dinâmica de democratização do planejamento e da gestão no país, tampouco para a sua ratificação como política de Estado.

Quanto à organização do sistema de ensino, em regime de colaboração, previsto na Constituição de 1988 (art. 23), pouco se avançou nesse sentido e, até o presente momento (2014), não foram estabelecidas, claramente, as normas para orientar o processo de cooperação entre os entes federados em matéria de educação e, também, não se regulamentou o regime 
de colaboração. Isso tem contribuído para a desarticulação entre os entes federados no que concerne à organização dos sistemas de ensino. Esse fenômeno é explicado por Araújo (2010), para quem a definição precisa das competências exclusivas dos entes federados, apresenta-se como uma tarefa excessivamente complexa e tem gerado diferentes conflitos.

Essa indefinição fez com que o novo Plano Nacional de Educação (2014-2024), aprovado pela Lei n. 13.005, de 25 de junho 2014, reiterasse essa matéria como pilar importante para garantir que as políticas educacionais atendam a um maior número de alunos com qualidade e equidade, estabelecendo, entre outras, as seguintes diretrizes: universalização do atendimento escolar, superação das desigualdades educacionais e melhoria da qualidade da educação. O novo Plano Nacional de Educação (2014) se propõe a criar as bases para a construção de uma educação nacional a partir da interação dos diversos sujeitos sociais que expressem, de forma plural, as suas concepções de mundo e de educação, para que, dessa forma, seja possível elaborar um referencial de qualidade para o país construído democraticamente. Em relação ao PNE (200 1), o PNE de (2014) traz um avanço significativo no que se refere à instituição do Sistema Nacional de Educação. $\bigcirc$ art. 13 prevê que,

[...] o poder público deverá instituir, em lei específica, contados 2 (dois) anos da publicação desta Lei, o Sistema Nacional de Educação, responsável pela articulação entre os sistemas de ensino, em regime de colaboração, para efetivação das diretrizes, metas e estratégias do Plano Nacional de Educação (BRASIL, 2014).

Esses foram os principais marcos legais que o governo brasileiro editou nos últimos anos, para reforçar o regime de colaboração entre os entes federados e traçar novos caminhos para a política educacional brasileira. Pode-se dizer que em produção de normativas, houve alguns avanços, no entanto eles foram insuficientes para estabelecer um novo padrão de regime de colaboração entre os entes federados. Em termos de implementação de políticas, embora embrionárias - existem algumas iniciativas que podem se constituir em elementos mobilizadores, no sentido de edificar mecanismos mais claros e pactuados entre os entes federados para a definição e implementação de políticas públicas, que contribuam para a garantia do direito constitucional de educação de qualidade para todos. 
No sentido de materializar as normativas concernentes ao regime de colaboração, o governo brasileiro criou vários programas. As primeiras iniciativas com o objetivo de fortalecer o regime de colaboração e estabelecer ações supletivas e redistributivas da União para com os entes subnacionais tiveram lugar no governo de Fernando Henrique Cardoso. Dentre esses programas pode-se destacar o Fundo de Manutenção e Desenvolvimento do Ensino Fundamental e de Valorização do Magistério (Fundef/1996), fundo de natureza contábil que recolhe impostos dos vários municípios dentro de um mesmo Estado e do próprio Estado e os redistribui de forma equânime entre todos com base no número de alunos de cada sistema. Esse fundo busca a equidade entre as diferentes regiões, estados e municípios, o que, supostamente, seria viabilizado pela sua lógica redistributiva. No entender de Azevedo (2002), o Fundef é uma iniciativa positiva e inovadora, pois possibilitou uma subvinculação específica de recursos, constitucionalmente vinculados, ao nível obrigatório de ensino. Além disso, imprimiu um caráter redistributivo a esses recursos, o que beneficiou os municípios mais pobres e, neles, melhorou as condições salariais dos docentes. O Fundef e o seu sucessor, o Fundeb, objetivam um impacto na distribuição de recursos financeiros entre sistemas estaduais e municipais e 60 embora tenham representado um avanço no sentido de lançar as bases para a implantação de um regime redistributivo, ainda está muito longe de atender a esse objetivo.

Costa, discutindo essa situação, faz a seguinte análise,

A estratégia de criação de fundos estaduais de equalização financeira foi inovadora e certamente teve um impacto relevante sobre as desigualdades gritantes no nível de gasto de sistemas estaduais e municipais de educação, e, principalmente, sobre a universalização das matrículas no ensino fundamental. No entanto, as limitações dessas iniciativas se tornam cada vez mais claras na medida em que os desafios no campo da educação vão além da eficiência do gasto (COSTA, 2010, p. 746).

Essas limitações estão associadas à complexidade da própria constituição do estado brasileiro, no qual há uma disparidade regional muito grande e de difícil equalização. No campo educacional, além da complementação financeira ser necessária, na maioria dos municípios brasileiros que dependem do fundo de participação, a solução dos problemas está associada, também, 
a fatores como a melhoria da infraestrututa das escolas e uma valorização mais digna dos profissionais da educação, no que se refere à melhoria do padrão de remuneração e qualificação bem como das condições de trabalho docente.

Outro mecanismo de planejamento, implementado pelo governo federal, ainda no governo de FHC (1999/2002), na tentativa de constituir um regime de colaboração foi a criação de um conjunto de programas e parâmetros nacionais para apoiar os estados e os municípios na organização dos seus sistemas de ensino. Entre os programas implementados pelo MEC para assessorar os entes federados, na elaboração dos seus planejamentos educacionais está o Plano de Desenvolvimento da Escola (PDE-Escola), concebido no âmbito do Fundoescola (200 1), de base gerencial, proveniente de um acordo firmado entre o Ministério da Educação e o Banco Mundial (1998), que tinha como objetivo modernizar a gestão educacional utilizando a lógica do mercado.

PDE-Escola, hoje PDE interativo, se constitui em um programa de complementação da União, tanto no aspecto financeiro quanto no assessoramento técnico. Por meio dele, se desenvolvem ações para ajudar as escolas na elaboração do planejamento estratégico visando à melhoria de seus indicadores e descritores de desempenho. Ao aderir ao PDE-Escola, as unidades escolares firmam um contrato com a União responsabilizando-se pelo cumprimento das metas que estabeleceram, por esse mecanismo; a União defende o discurso da modernização da gestão e atribui aos entes locais a responsabilidade pelo sucesso ou insucesso das suas ações. Por meio de uma política definida no âmbito central, o estado nação, procura instituir o regime de colaboração. Na verdade, como afirma Araújo (2010, p. 238), nas políticas educacionais brasileiras tem prevalecido a definição de normas de colaboração formuladas a partir do governo central, " [...] erroneamente confundidas como passos importantes ou avanços para a regulamentação do regime de colaboração."

Em 2007, para dar organicidade e coesão aos vários programas que já vinham sendo desenvolvidos, pela União, o governo Lula da Silva, institui o Plano de Desenvolvimento da Educação (PDE), que, de acordo com documentos elaborados pelo MEC, pode ser considerado um plano executivo ou um conjunto de programas que visam dar consequência às metas estabelecidas pelo Plano Nacional de Educação, objetivando, sobretudo, a melhoria da educação brasileira. 
Embora o texto do Plano de Desenvolvimento da Educação apresente as razões, princípios e programas como uma inovação, ele traz poucas novidades. Segundo Saviani (2007, p. 1233), o PDE, além de não se constituir em um plano ele serve para agregar em um "[...] grande guarda chuva [...]" todos os programas desenvolvidos pelo MEC. O PDE, na realidade, se constitui em um documento que demonstra o quanto os vários programas educacionais, independente do nível de ensino a que se destinam, fazem parte de um mesmo conjunto de diretrizes. Ao mesmo tempo, programas já existentes, considerados eficientes para o fortalecimento da organicidade gerencial são aprofundados, como é o caso do PDE-escola, que de um programa pontual, passou a assumir abrangência nacional.

Esse plano contempla mais de quarenta programas, mas é dado destaque às ações que evidenciam as conexões mais relevantes no que diz respeito ao delineamento da políitica com base nos princípios já mencionados, dentre eles: a reorganização do sistema de avaliação com a criação do ldeb e o princípio da responsabilização; a reorganização do financiamento com criação do Fundeb; a criação do sistema nacional de formação de professores e estabelecimento do piso salarial nacional da categoria e, por fim, a criação

62 de um instrumento jurídico que estabelece um novo regime de colaboração entre os entes federados, agora, firmados por meio de contrato entre a união e os vários entes federados.

Nesse contexto, em abril de 2007, para atender às exigências internacionais e nacionais de melhoria dos índices educacionais, simultaneamente ao PDE o governo aprovou, por meio do Decreto n 6.094, o Plano de Metas Compromisso Todos Pela Educação, ressaltando, no seu art. $1^{\circ}$, que o Plano "[...] é a conjugação dos esforços da União, Estados, Distrito Federal e Municípios, atuando em regime de colaboração, das famílias e da comunidade, em proveito da melhoria da qualidade da educação básica" (BRASIL, 2007, p. 011.

Ainda nesse Plano, o governo federal institui, no art. $3^{\circ}$, que a qualidade da educação básica será aferida, com base no Índice de Desenvolvimento da Educação Básica, calculado e divulgado periodicamente pelo Inep (BRASIL, 2007). Essa medida resultou em sérias críticas pela comunidade acadêmica, entre elas, sobressai a de Voss (201 1), para quem, esse indicador de qualidade escamoteia as reais condições das escolas, dos professores e dos alunos. Nesse sentido, afirma, 
[...] ao fixar a avaliação da qualidade do ensino ao IDEB, que se baseia na análise de desempenho pelos resultados em termos de notas em testes padronizados e em taxas de evasão e repetência, certos fatores conjecturais, como as condições socioeconômicas e culturais das redes, das escolas e dos alunos as condições de trabalho dos professores e demais profissionais do ensino, são negligenciados (VOSS, 201 1, p. 58).

Pode-se considerar que o Plano de Metas Compromisso Todos pela Educação é um programa estratégico do Plano de Desenvolvimento da Educação (PDE). Apresentado como parte do Programa de Aceleração do Crescimento (PAC), ele é caracterizado como o PAC da Educação. Dentre os princípios que pautam o Plano de Desenvolvimento da Educação, estão: a visão sistêmica da educação, a partir da qual se busca considerar a interdependência e importância entre todos os níveis e modalidades de ensino; territorialidade, por meio do qual se busca a unidade do sistema nacional sem desconsiderar a multiplicidade que caracteriza o conjunto dos sistemas, como caminho para a qualidade; responsabilização e mobilização social, que defende o envolvimento da classe política e da sociedade como condição indispensável para qualificar os processos educativos.

No que se refere à instituição do regime de colaboração, pode-se considerar que o PDE foi uma iniciativa importante, pois, por meio dele, a União coloca à disposição dos estados e municípios instrumentos de avaliação e de implementação de políticas buscando, por meio destes, desempenhar, com maior eficiência, a função redistributiva e supletiva atribuída pela Constituição de 1988, de forma a garantir a equalização de oportunidade e padrão mínimo de qualidade (BRASIL, 2007).

Essa política pública de educação está em pleno processo de implementação, por meio do Plano de Ações Articuladas (PAR) o qual deve ser elaborado por estados e municípios que aderiram ao Plano de Metas Compromisso Todos pela Educação. O PAR tem um caráter plurianual o que possibilita, teoricamente, o desenvolvimento do regime de colaboração, procurando reduzir a descontinuidade das ações. Os municípios e estados que assinaram o termo de adesão ao Plano de Metas, elaboraram um diagnóstico da situação educacional para, posteriormente, formular o seu Plano de Ações Articuladas. Esse Plano se estrutura em 4 (quatro) dimensões: a gestão educacional; a formação de professores e dos profissionais de serviço e 
apoio escolar; a prática pedagógica e a avaliação; a infraestrutura e recursos pedagógicos.

No termo de cooperação técnica, consta como competência do MEC a assistência técnica (por um período ou pelos quatro anos), bem como assistência financeira. Quanto aos programas de transferência de recursos financeiros para o município, é necessária a assinatura de convênios, os quais podem variar conforme a ação e obedecem às normas específicas para transferências federais de qualquer tipo, bem como as normas do FNDE. O planejamento fica registrado no Sistema Integrado de Monitoramento do Ministério da Educação (SIMEC), ambiente virtual criado pelo MEC para inserir o diagnóstico e o PAR dos estados e municípios.

No que se refere à modernização da gestão educacional, o PAR contempla uma perspectiva gerencialista, na qual é mais importante o produto do que o processo. Ao perseguir as metas estabelecidas utilizando-se dos instrumentos, estrategicamente elaborados pelos planejadores centrais, a gestão educacional se aproxima muito mais de um modelo de gestão gerencial, do que de uma gestão democrática e participativa. Nesse cenário, o envolvimento da comunidade escolar na definição das ações a serem realizadas no 64 âmbito local é para imprimir legitimidade às ações definidas em âmbito central, o que compromete a participação efetiva da sociedade civil, dos professores e da comunidade estudantil nas decisões que dizem respeito às peculiaridades locais. Os municípios se restringem a escolher programas que foram concebidos em âmbito central, o que limita a sua capacidade de autonomia em criar programas mais condizentes com as suas realidades.

Plano de Ações Articuladas, pelas suas propostas e objetivos, poderia contribuir para o estabelecimento de um regime de cooperação entre os entes federados, no entanto concorda-se com Farenzena (2006), que, ao analisar as relações intergovernamentais estabelecidas entre os entes federados, na atualidade, conclui que essa relação é muito mais de transferência, aos estados e/ou municípios, da responsabilidade pela implementação ou gestão de políticas definidas em nível federal, do que a descentralização por transferência de capacidade fiscal e de poder de decisão na implementação de políticas aos estados e municípios. Dessa forma, as políticas adotadas pelo governo federal têm contribuído para reforçar a ação centralizadora da União, configurando um federalismo centrípeto, no qual a descentralização de poder e a autonomia dos entes subnacionais ficam muito reduzidas. 
Essa lógica tem trazido certo protagonismo para a União que tem procurado se responsabilizar por instituir um federalismo cooperativo no campo educacional, pelo menos em nível de discurso. Na prática os programas e as ações implementadas têm reforçado o federalismo centralizado, no qual a União concebe as ações que serão ofertadas aos municípios e a estes cabe notadamente a função executora das políticas educacionais, com perda significativa da autonomia municipal.

\section{Algumas considerações para continuar o debate}

Brasil, ao longo de sua história, adotou diferentes modelos de organização federativa. Em determinadas conjunturas, assume características de um federalismo centrípeto no qual as relações intergovernamentais se caracterizam como verticais, dificultando o compartilhamento na formulação e execução de políticas pelos entes federados; em outras conjunturas, assume características centrífugas privilegiando a descentralização das ações para as unidades subnacionais, concedendo maior autonomia para os estados e os municípios, estabelecendo, assim, uma relação de negociação e cooperação entre as esferas de poder.

Essa inconstância na forma de agir tem dificultado o estabelecimento de um regime federalista de cooperação, no qual as relações intergovernamentais entre os entes federados permitem um maior equilíbrio entre eles, o que tem exigido do governo central uma postura de maior eficiência no exercício da coordenação federativa. Desse modo, a sua concretização pressupõe a elaboração de normas nas quais estejam claramente definidas as competências e as responsabilidades dos entes federados. A Constituição Federal de 1988 trouxe alguns avanços nesse sentido, na medida em que estabeleceu diretrizes para regular um pacto federativo, atribuindo autonomia político-administrativa para os entes federados. No entanto, não há, na CF de 1998, clareza suficiente no estabelecimento de competências para cada ente federado, tendo prevalecido, segundo Novelino (2013), o princípio da predominância de interesse, o que, por sua vez, tem fragilizado a coordenação federativa.

As iniciativas do governo federal caminham no sentido de alcançar a função que the é atribuída pelo regime federativo e instituir relações intergovernamentais de cooperação entre os entes federados. Nesse intuito, e tendo como 
referência a CF de 1988, a Lei de Diretrizes e Bases da Educação, n. 9.394, de 20 de dezembro de 1996, como também as várias Emendas Constitucionais aprovadas posteriormente, diversos Programas foram implementados procurando resgatar o protagonismo da União em um regime federativo. No entanto, o caminho escolhido precisa ser aperfeiçoado. Na atualidade, a união se coloca como centralizadora e definidora das políticas que serão executadas em níveis locais, contribuído para aumentar a situação de dependência em relação ao centro. Como consequência dessa postura, os municípios continuam com autonomia limitada para a elaboração de suas políticas educacionais e passam a depender, cada vez mais, da assistência técnica e financeira da União, que utiliza o discurso de modernização gerencial para induzir a participação dos municípios na implementação e execução de políticas concebidas fora do âmbito local.

Essa postura é visível no Plano Compromisso Todos pela Educação e no Plano de Ações Articuladas, estratégias utilizadas, pelo governo federal, para viabilizar o regime de colaboração e para operacionalização das políticas educacionais. Com esses mecanismos, o governo tem adotado uma postura centralizadora e indutora da política educacional do País, com o discurso de

66 instituir um Sistema Nacional de Educação. Demarca-se, todavia, que o Sistema Nacional de Educação poderá cumprir papel importante na resolução de problemas que persistem, historicamente, na educação brasileira caso ele seja construído democraticamente. Por isso, ele deve ser resultante de um debate que inclua, desde a sua concepção, todos os entes federados na perspectiva de se construir regras pactuadas coletivamente. Isso porque o sistema nacional de educação, como afirma o Saviani (201 1, p. 17), "[...] não é do governo federal, mas é da federação, portanto, dos próprios entes federados que o constrói conjuntamente e participam, também, em conjunto de sua gestão."

\section{Notas}

1 Emenda Constitucional n. 14/1996, modifica os arts. 34, 208, 211 e 212 da Constituição Federal e dá nova redação ao art. 60 do Ato das Disposições Constitucionais Transitórias.

2 A Emenda Constitucional $n^{\circ}$ 59/2009, no seu art. $1^{\circ}$, amplia a oferta da educação básica obrigatória dos quatro aos dezessete anos de idade além de ampliar a abrangência dos programas suplementares para todas as etapas da educação básica. $\bigcirc$ art. $2^{\circ}$ estabeleceu que a oferta do serviço educacional é competência comum da União, dos estados, do Distrito Federal e dos municípios, devendo ser realizado em forma de colaboração. Nesse sentido, a Emenda 59 
recupera para a União o papel de coordenador da ação dos entes federados no estabelecimento do regime de colaboração, que, na Constituição de 1988, tinha ficado, apenas, a cargo dos estados e municípios.

\section{Referências}

ABRÚCIO, Fernando Luiz. A reconstrução das funções governamentais no federalismo brasileiro. In: HOFMEISNTER, Wilhelm; CARNEIRO, José Mário Brasiliense (Org.). Federalismo na Alemanha e no Brasil. São Paulo: Fundação Konrad Adenauer, 2001, p. 95-108.

ABRÚCIO, Fernando Luiz; FRANZESE, Cibele. Federalismo e políticas públicas: o impacto das relações intergovernamentais no Brasil. In: ARAÚJO, Maria de Fátima Infante; BEIRA, Ligia. (Org.). Tópicos de economia paulista para gestores públicos. São Paulo: Edições FUNDAP, 2007.

A dinâmica federativa da educação brasileira: diagnóstico e propostas de aperfeiçoamento. In: OLIVEIRA, Romualdo Portela de; SANTANA, Wagner (Org.). Educação e federalismo no Brasil: combater as desigualdades, garantir a diversidade. Brasília: UNESCO, 2010.

ABRÚCIO, Fernando Luiz. A coordenação federativa no Brasil: a experiência do período FHC e os desafios do governo Lula. Revista Sociologia e Política, Curitiba, n 24, p. 41-67, jun. 2005.

ALMEIDA, Maria Hermínia Tavares. Federalismo, democracia e governo no Brasil: ideias, hipóteses e evidências. Revista Brasileira de Informação Bibliográfica em Ciências Sociais, São Paulo, n. 51, p. 13-34, jan./jun. 2001.

ANDERSON, George. Federalismo: uma introdução. Tradução Ewandro Magalhães e Fátima Guerreiro. Rio de Janeiro: FGV, 2009.

ARAÚjO, Gilda Cardoso de. Direito à educação básica: a cooperação entre os entes federados. Retratos da Escola, Brasília, v. 4, n. 7, p. 231-24 1, jul./ dez. 2010. 
ARRETCHE, Marta. Federalismo e políticas sociais no Brasil: problemas de coordenação e autonomia. São Paulo em Perspectiva, São Paulo, v. 18, n. 2, p. 17-26, abr./jun. 2004.

AZEVEDO, Janete Maria Lins de. Implicações da Nova Lógica de Ação do Estado para a Educação Municipal. Educação \& Sociedade, Campinas, v. 23, n. 80, p. 49-71, set. 2002. Disponível em: www.scielo.br. Acesso em: 10 set. 2014 .

BERCOVICl, Gilberto. Desigualdades regionais, estado e constituição. São Paulo: Max Limonad. 2003.

BRASIL. Presidência da República. Casa Civil. Constituição da República Federativa do Brasil de 1988. Disponível em: http://www. planalto.gov.br/ ccivil_03/constituicao/constituicao.htm. Acesso em: 15 set. 2014.

Presidência da República. Casa Civil. Emenda Constitucional n ${ }^{\circ} 14$, de 12 de dezembro de 1996. Modifica os arts. 34, 208, 211 e 212 da Constituição Federal e dá nova redação ao art. 60 do Ato das Disposições constitucionais Transitórias. Disponível em: http://www. planalto.gov.br/cci68 vil_03/constituicao/Emendas/Emc/emcl4.htm. Acesso em: 2 set. 2014.

Presidência da República. Casa Civil. Emenda Constitucional n ${ }^{\circ} \mathbf{5 3}$ de 19 de dezembro de 2006. Disponível em: www.fnde.gov.br/fndelegis/ action. Acesso em: 5 set. 2014

Presidência da República. Casa Civil. Lei n ${ }^{\circ}$ 11.494, de 20 de junho de 2007. Regulamenta o Fundo de Manutenção e Desenvolvimento da Educação Básica e de Valorização dos Profissionais da Educação - FUNDEB. Brasília, DF, 2007. Disponível em http://www. planalto.gov.br/ccivil_03/_ ato2007-2010/2007/lei/l1 1494.htm. Acesso em: 2 set. 2014.

Ministério da Educação. O Plano de Desenvolvimento da Educação. Razões, princípios e programas. Brasília: MEC, 2007.

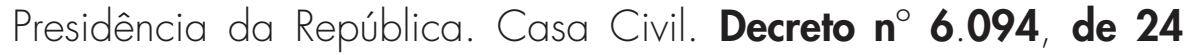
de abril de 2007. Dispõe sobre a implementação do Plano de Metas Compromisso Todos pela Educação. Disponível em: http:www.planalto.gov. br. Acesso em: 14 set. 2014. 
Lei nº 9.394 de 20 de dezembro de 1996. Estabelece as diretrizes e bases da educação nacional (LDB). Diário Oficial [da] União, Poder Executivo, Brasília, DF, 23 de dezembro de 1996. Seção 1, p. 27833.

. Presidência da República. Lei n ${ }^{\circ}$ 10.172, de 09 de janeiro de 2001. Aprova o Plano Nacional de Educação e dá outras providências. Disponível em: http://www.planalto.gov.br/ccivil_03/leis/leis_2001/110172.htm. Acesso em: 2 out. 2014.

. Ministério da Educação. Construindo o Sistema Nacional Articulado de Educação: $\bigcirc$ Plano Nacional de Educação, Diretrizes e Estratégias de Ação. Documento referência CONAE, 2010. Brasília, DF, 2008.

Presidência da República. Casa Civil. Emenda Constitucional n 59, de 11 de novembro de 2009. Disponível em: http:www. planalto.gov. br. Acesso em: 12 set. 2014.

. Presidência da República. Lei n 13.005, de 25 de junho de 2014. Aprova o Plano Nacional de Educação e dá outras providências. Disponível em: http://www.planalto.gov.br/ccivil_03/leis/leis_2001/110172.htm. Acesso em: 2 out. 2014.

CAFFARATE, Viviane Machado. Federalismo: uma análise sobre uma temática atual. Jus Navigand, Teresina, v. 7, n. 59, s/p. out. 2002. Disponível em: http://jus.com.br/Revista/3449. Acesso em: 10 jun. 2014.

COSTA, Valeriano Mendes Ferreira. Federalismo e relações intergovernamentais: implicações para a reforma da educação no Brasil. Educação \& Sociedade, Campinas, v. 31 , n. 1 12, p.729-748, jul./set. 2010.

CUNHA, Rosani Evangelista da. Federalismo e relações intergovernamentais: os consórcios públicos como instrumento de cooperação federativa. Revista do Servidor Público, Brasília, v. 55, n. 3, p. 6-34, jul./set. 2004.

CURY, Carlos Roberto Jamil. A questão federativa e a educação escolar. In: OLIVEIRA, Romualdo Portela de; SANTANA, Wagner (Org.). Educação e federalismo no Brasil: combater as desigualdades, garantir a diversidade. Brasilia: UNESCO, 2010. 
DALLARI, Dalmo de Abreu. Elementos de teoria geral do Estado. 19. ed. São Paulo: Saraiva, 1995.

DOURADO, Luiz Fernandes. Plano Nacional de Educação como política de Estado: antecedentes históricos, avaliação e perspectivas. In: DOURADO, Luiz Fernandes (Org.). Plano Nacional de Educação (201 1-2020): avaliação e perspectiva. Goiânia: Editora UFG/Autêntica, 2011.

DRIGO, Leonardo Godoy. Competências legislativas concorrentes: o que são normas gerais? Disponível em: <www Jus.com. br/artigos/24557/competências legais, 2013 >. Acesso em: 10 ago. 2014.

ELAZAR, Daniel. Exploring federalism. Tuscaloosa: University of Alabama, 1987.

FARENZENA, Nalú. A política de financiamento da educação básica: rumos da legislação brasileira. Porto Alegre: UFRGS, 2006.

FRANZESE, Cibele. Federalismo cooperativo no Brasil: da Constituição de 1988 ao sistema de políticas públicas. 2010. 210 f. Tese (Doutorado 70 em Administração Pública) - Escola de Administração de Empresas de São Paulo. São Paulo, 2010.

MARQUES, Arnóbio. Federalismo e educação: novos rumos e perspectivas. Retratos da Escola, Brasília, v. 6, n. 10, p. 11-19, jan./jun. 2012. (Entrevista).

NOVELINO, Marcelo. Manual de direito constitucional. 8. ed. Rio de Janeiro: Forense/São Paulo: Método, 2013.

OLIVEIRA, Romualdo Portela de; SOUZA, Sandra Zákia. In: OLIVEIRA, Romualdo Portela de; SANTANA, Wagner (Org.). Educação e federalismo no Brasil: combater as desigualdades, garantir a diversidade. Brasilia/ Unesco, 2010.

OLIVEIRA, Romualdo Portela de; SANTANA, Wagner. In: OLIVEIRA, Romualdo Portela de; SANTANA, Wagner (Org.). Educação e federalismo no Brasil: combater as desigualdades, garantir a diversidade. Brasília: UNESCO, 2010. 
PIERSON, Paul. Fragmented Welfare States: Federal Institutions and the Development of Social Policy. Governance, Cambridge, v. 8, n. 4, p. 448478, oct. 1995.

SAVIANI, Dermeval. O Plano de Desenvolvimento da Educação: análise do projeto do MEC. Educação \& Sociedade, Campinas, v. 28, n. 100, p. 1231-1255, out. 2007.

\section{SAVIANI, Dermeval. Plano Nacional de Educação, a questão federativa}

e os municípios: o regime de colaboração e as perspectivas da educação brasileira. São Paulo: Grabois, 2011.

SOUZA, Alexis Sales de Paula e. A origem do Federalismo brasileiro. Jus Navigandi, Teresina, v. 15, n. 2642, s/p. 25 set. 2010. Disponível em: <http://jus.com.br/artigos/17486>. Acesso em: 23 set. 2014.

VOSS, Dulce Maria da Silva. O Plano de Desenvolvimento da Educação (PDE): contextos e discursos. Cadernos de Educação, Pelotas, v. 38, p. 43-67, jan./abr. 2011.

Prof. Dr. Antônio Cabral Neto

Universidade Federal do Rio Grande do Norte Departamento de Fundamentos e Políiticas da Educação

Programa de Pós-Graduação em Educação Grupo de Pesquisa | Política e Gestão da Educação E-mail | cabraln@ufrnet.br

Profa. Dra. Alda Maria Duarte Araújo Castro Universidade Federal do Rio Grande do Norte Departamento de Fundamentos e Políticas da Educação

Programa de Pós-Graduação em Educação Grupo de Pesquisa | Política e Gestão da Educação E-mail | alda@ufrnet.br 
Artigo

Federalismo e educação no Brasil: subsídios para o debate

Profa. Dra. Maria Goretti Cabral Barbalho

Universidade Federal do Rio Grande do Norte Departamento de Fundamentos e Políticas da Educação

Programa de Pós-Graduação em Educação Grupo de Pesquisa | Política e Gestão da Educação E-mail |gorettic@ufrnet.br

Recebido 10 nov. 2014 Aceito 10 fev. 2015 